\section{OPEN ACCESS}

Edited by:

Steven H. Lin,

University of Texas MD Anderson Cancer Center, United States

Reviewed by: Smith Apisarnthanarax, University of Washington, United States

Salma Jabbour,

Rutgers Biomedical and Health Sciences, United States

Michael David Chuong,

Baptist Health South Florida,

United States

*Correspondence: Tae Hyun Kim k2onco@ncc.re.k

${ }^{\dagger}$ These authors have contributed equally to this work

Specialty section:

This article was submitted to Radiation Oncology,

a section of the journal

Frontiers in Oncology

Received: 07 February 2020 Accepted: 26 March 2020 Published: 28 April 2020

Citation:

Kim TH, Park J-W, Kim BH, Oh ES,

Youn SH, Moon SH, Kim SS,

Woo SM, Koh Y-H, Lee WJ and Kim DY (2020) Phase II Study of

Hypofractionated Proton Beam Therapy for Hepatocellular Carcinoma. Front. Oncol. 10:542 doi: 10.3389/fonc.2020.00542

\title{
Phase II Study of Hypofractionated Proton Beam Therapy for Hepatocellular Carcinoma
}

\begin{abstract}
Tae Hyun Kim ${ }^{1,2 * t}$, Joong-Won Park ${ }^{1 \dagger}$, Bo Hyun Kim ${ }^{1 \dagger}$, Eun Sang $\mathrm{Oh}^{2}$, Sang Hee Youn ${ }^{2}$, Sung Ho Moon ${ }^{2}$, Sang Soo Kim ${ }^{2}$, Sang Myung Woo ${ }^{1}$, Young-Hwan Koh ${ }^{1}$, Woo Jin Lee ${ }^{1}$ and Dae Yong Kim ${ }^{2}$
\end{abstract}

${ }^{1}$ Center for Liver Cancer, Research Institute and Hospital, National Cancer Center, Goyang, South Korea, ${ }^{2}$ Center for Proton Therapy, Research Institute and Hospital, National Cancer Center, Goyang, South Korea

Background: Proton beam has an excellent depth dose distribution due to its unique physical properties, and thus proton beam therapy (PBT) has been tried and showed promising outcomes in hepatocellular carcinoma (HCC). The purpose of this phase II study is to evaluate the efficacy of hypofractionated PBT in HCC.

Methods: The eligibility criteria for this study were as follows: patients with HCC lesion(s) who were failed after, were difficult to treat with, or refused to other local treatments; tumor size and number of $\leq 7$ and $\leq 2 \mathrm{~cm}$, respectively, and HCC lesion(s) of $\geq 2 \mathrm{~cm}$ from gastrointestinal organs; Child-Pugh score of $\leq 7$; Eastern Cooperative Oncology Group performance status $\leq 1$; and age $\geq 18$ years. The prescribed dose of PBT was 70 Gy equivalent in 10 fractions. The primary endpoint was 3-year local progression-free survival (LPFS) rate.

Results: Forty-five patients were prospectively enrolled, and there were 35 men and 10 women with a median age of 63 years (range, 46-78 years). Thirty-seven patients had recurrent and/or residual disease, and eight patients had treatment-naive disease. All patients received the planned treatments without treatment interruption, and grade $\geq 3$ acute toxicity did not occur. The median follow-up duration was 35.1 months (range, 11.2-56.3 months) and local progression occurred in two patients (8.7\%). The 3-year rates of LPFS and overall survival (OS) were 95.2\% (95\% confidence interval $[\mathrm{Cl}]$, 89.1\%-100\%) and 86.4\% (95\% Cl, 72.9-99.9\%), respectively.

Conclusion: Hypofractionated PBT showed promising LPFS and OS, and further studies are warranted to compare PBT with other local modalities.

Keywords: hepatocellular carcinoma, overall survival, local progression-free survival, proton beam therapy, radiotherapy

\section{INTRODUCTION}

Hepatocellular carcinoma (HCC) patients mostly have an underlying chronic liver disease resulting from hepatitis B (HBV) and C virus infection, alcoholic liver disease, nonalcoholic fatty liver disease, and so on. Intrahepatic disease progression is the main cause of death in nonmetastatic HCC patients (1). Thus, effective local treatments in these patients are crucial. Various local treatment options for HCC patients, such as surgical resection, liver transplantation, local ablative treatments including thermal ablation and percutaneous ethanol injection, transarterial chemoembolization (TACE), radioembolization, and so on, have been available (2-5), but many 
factors including tumor burdens, tumor characteristics, underlying liver function, and patient comorbidities limit the treatment options.

With recent technological advances in radiotherapy (RT) and biologic understanding of liver tolerance to RT, modern sophisticated RT techniques, such as three-dimensional conformal RT, intensity-modulated RT, and stereotactic body RT (SBRT), have made it possible to deliver high doses of radiation to tumor(s) and reduce radiation doses to surrounding noncancerous tissues including the remaining normal liver and gastrointestinal (GI) organs, and these have shown promising outcomes in HCC patients with/without tumor vascular thrombosis (TVT) (6-9). Compared with RT with X-ray, proton beam therapy (PBT), due to the inherent physical properties of the proton beam (called Bragg peaks), has an excellent depth dose distribution, which can increase the dose to the tumor while maintaining the radiation dose in the noncancerous portion of the liver (10-12). Recently, PBT with various fractionations (i.e., 4-34 fractions) has been attempted and showed encouraging outcomes (13-24). Theoretically, hypofractionated RT can potentially improve the therapeutic ratio compared with conventional fractionated RT by reducing the cancer cell proliferation within the tolerances of surrounding noncancerous tissues and shortening the overall treatment time. Based on this rationale, this single-institutional, single-arm, prospective study was conducted to evaluate the efficacy of hypofractionated PBT for HCC patients.

\section{MATERIALS AND METHODS}

\section{Patients}

Patients were enrolled in a prospective clinical trial. The eligibility criteria for this study were as follows: (i) HCC was diagnosed with pathological confirmation or radiologic findings and serum $\alpha$-fetoprotein concentrations of $\geq 200 \mathrm{ng} / \mathrm{mL}$ based on the guidelines of the Korean Liver Cancer Study Group and the National Cancer Center (NCC) (3); (ii) patients with primary or recurrent HCC lesions who were failed after, were difficult to treat with, or refused to other local treatments including surgical resection, radiofrequency ablation (RFA), TACE, and so on; (iii) the largest diameter and number of target lesion(s) were $\leq 7$ and $\leq 2 \mathrm{~cm}$, respectively, and targeted lesion(s) were $\geq 2 \mathrm{~cm}$ from GI organs; (iv) no history of prior RT to targeted lesion(s); (v) no evidence of extrahepatic metastasis; (vi) ChildPugh score of $\leq 7$ without uncontrolled ascites; (vii) Eastern Cooperative Oncology Group performance status of $\leq 1$; (viii) age of $\geq 18$ years; and (ix) adequate bone marrow (white blood cell count $1,500 / \mathrm{mm}^{3}$, platelet count $30,000 / \mathrm{mm}^{3}$, and hemoglobin $7.5 \mathrm{~g} / \mathrm{dL}$ ) and liver (total bilirubin $\leq 3.0 \mathrm{mg} / \mathrm{dL}$, and aspartate aminotransferase and alanine aminotransferase $<5.0 \times$ upper limit of normal) functions. Clinical and tumor stage was classified by the Barcelona Clinic Liver Cancer (BCLC) (5) and the Modified Union for International Cancer Control (mUICC) (25) staging classification, respectively. This study was approved by the institutional review board of NCC (NCC20150042) and registered at www.clinicaltrials.gov (NCT02395523). Written informed consent was obtained for all patients before enrollment.

\section{Treatment}

The simulation, plan, and treatment procedures of PBT have been previously reported $(11,13-15,17,18)$. Briefly, a fourdimensional computed tomography (CT) scan with contrast was performed in all patients under monitoring the respiration signals by a real-time position management (RPM) system (Varian Medical Systems, Palo Alto, CA, USA), and all obtained CT images were resorted into 10 equally spaced respiratory phases. The gross tumor volume (GTV) was delineated in the average intensity projection CT images, reconstructed with the CT images of gated (exhalation) phases (30\% of total respiratory cycle). The internal target volume (ITV) was determined as the sum of the GTVs without margin from GTV for clinical target volume $(11,13-15,17,18,21,26)$, and the contours of the organs at risk (OARs) were delineated in each CT image during the gated phases. The planning target volumes (PTVs) included the ITV plus a margin of $5-7 \mathrm{~mm}$ in all directions. Typically, PBT plans (version 8.1; Varian Medical Systems) were performed with two to four (median of three) $230-\mathrm{MeV}$ proton beams (Proteus 235; Ion Beam Applications, S.A., Louvain-la-Neuve, Belgium) using the double-scattering mode to design so that $100 \%$ of each prescribed dose would cover at least 95\% of the PTV. The delivered irradiated doses of PBT to target and OARs were described in gray equivalents $[\mathrm{GyE}=$ physical dose of proton (in gray) $\times$ relative biologic effectiveness of proton (1.1)] and the equivalent dose in 2-Gy fractions [EQD2 $\left(\mathrm{GyE}_{10}\right.$ or $\left.\mathrm{GyE}_{3}\right)$ $=$ total dose $\times(\{$ fraction dose $+\alpha / \beta\} /\{2+\alpha / \beta\}), \alpha / \beta$ of 3 and 10 for the late and acute effects, respectively] (27). The prescribed dose to PTV was $70 \mathrm{GyE}$ (EQD2, 99.2 $\mathrm{GyE}_{10}$ ) in 10 fractions considering dose-fractionation regimens of our studies [50-72 GyE in 10-24 fractions (EQD2, 52.1-91.3 $\left.\mathrm{GyE}_{10}\right)$ ] (13-18) and those of other studies [24-91 GyE in 6-30 fractions (EQD2, 28$\left.103.5 \mathrm{GyE}_{10}\right)$ (19-23). The dose volume constraints to the OARs were described in detail in our previous reports $(11,13-18,28)$. The relative volumes of the remaining normal liver (total liverGTV) and total liver receiving more than $27 \mathrm{GyE}$ were limited to $<50$ and $60 \%$, respectively, and the absolute volumes of the bowel and stomach receiving more than 35 and $37 \mathrm{GyE}$, respectively, were limited to $<2 \mathrm{~cm}^{3}$. At each treatment, all patients were asked to fast for at least $4 \mathrm{~h}$ before treatment to diminish intrafractional and interfractional uncertainties. Each patient's position and isocenter were verified using digital orthogonal fluoroscopy, and radiation was delivered during the gated (exhalation) phases under monitoring the respiration signals by RPM system.

\section{Evaluation and Statistical Considerations}

During PBT, patients were assessed weekly and, after completion of PBT, at the first month, every 3 months for the first 2 years, every 6 months up to 5 years, and yearly thereafter. Clinical, laboratory, and radiological examinations were performed at each follow-up. The tumor responses were assessed according to the modified Response Evaluation Criteria in Solid Tumors criteria (29) by comparing pre- and post-PBT CT/MRI scans, and the severity of adverse effects was graded using the Common Terminology Criteria for Adverse Events (version 4.0).

The primary endpoint of this study was local progressionfree survival (LPFS), and we set the expected 3-year LPFS in 




FIGURE 1 | CONSORT diagram.

patients treated with $\mathrm{PBT}$ at $80 \%$ or higher, considering results of our previous and other studies $(17,19,22,23,30)$, with a threshold of $15 \%$. With a power of $80 \%$, a type I error level of $10 \%$ and a follow-up loss rate of $10 \%, 45$ patients were required for enrollment. The definition of local, intrahepatic, and distant progression was a regrowth or new tumor within the PTV, within liver outside of the PTV, and extrahepatic sites, respectively. The times of LPFS, progression-free survival (PFS), and overall survival (OS) were determined from the commencement date of PBT to the date of local progression, disease progression or death, and death or last follow-up, respectively. Survival was estimated using the Kaplan-Meier method, and the difference in the survival curve was evaluated with the log-rank test in univariate analysis. Statistical significance was set to a $p<0.05$, and all statistical tests were performed using STATA software (version 14.0; StataCorp, College Station, TX, USA).

\section{RESULTS}

Between March 2015 and September 2018, 137 patients were assessed the eligibility for this trial. Of these, 50 patients participated in other competitive trials, 42 patients did not agree to inform consent, and the remaining 45 patients were enrolled and analyzed (Figure 1). Patient characteristics at the time of PBT are summarized in Table 1. Most $(n=37,82.2 \%)$ patients, except eight patients (17.8\%) who were treatment-naive due to difficultto-treat lesions or refused to undergo other local treatments, had recurrent and/or residual tumor(s) in the PBT site, and the number of lesions treated with PBT was one and two in 42 and three patients, respectively. The median time of follow-up was 35.1 months (range, 11.2-56.3 months).

Of 45 patients, all treated lesions eventually reached complete response (CR), and the median time to $\mathrm{CR}$ was 5.1 months [95\% confidence interval (CI), 4.3-6.3 months] (range, 1-19.6 months) (Figure 2). With increasing tumor size $[2 \mathrm{~cm}(n=28)$,
$2.1-4 \mathrm{~cm}(n=14)$, and $>4 \mathrm{~cm}(n=3)]$, the median times to CR increased [4.6 months (95\% CI, 4.2-6.2 months), 6.4 months (95\% CI, 4.0-9.7 months), and 5.1 months (95\% CI, 5.1-10.6 months), respectively], but these differences were not significant $(p=0.675)$. At the time of analysis, 41 patients were alive, and four died of disease progression. Of 45 patients, disease progression occurred in 23 patients (51.1\%) as follows: the initial sites of disease progression were local sites in two patients $(8.7 \%)$, intrahepatic sites in 17 patients $(73.9 \%)$, and distant sites in four patients (17.4\%), and all of the sites of disease progression at the time of analysis were local sites in two patients $(8.7 \%)$, intrahepatic sites in 19 patients (82.6\%), and distant sites in eight patients $(34.8 \%)$ (Figure 3 ). The median times to local, intrahepatic, and distant disease progression were 12.5 months (range, 10.5-14.4 months), 15.4 months (range, 2-30.1 months), and 20.6 months (range, 1.5-22.5 months), respectively. After disease progression was confirmed, 22 of 23 patients (95.7\%), except for one patient due to poor performance status, were treated with salvage treatments, such as one or combinations of local and/or systemic treatments (i.e., surgical resection, RFA, TACE, PBT, RT, sorafenib, etc.).

The 3-year rates of LPFS, PFS, and OS were 95.2\% (95\% CI, $89.1 \%-100 \%)$, $45.2 \%$ (95\% CI, 29.9\%-60.5\%), and 86.4\% (95\% CI, 72.9\%-99.9\%), respectively (Figure 4). All pretreatment characteristics were not significantly related to LPFS in the univariate analysis (Table 2). Patients with recurrent lesion(s), previous history of treatment to PBT site(s) or other site(s), and mUICC stage II/III had a trend toward lower PFS than those with primary lesion(s), no history of treatment to PBT site(s) or other site(s), and mUICC stage I, but these differences were not statistically significant in the univariate analysis because of the small number of study populations $(n=45)(p>0.05$ each) (Table 2). The patients with HBV had significantly higher PFS than the others in the univariate analysis ( $p<0.05$ each) (Table 2). All pretreatment characteristics were not significantly related to OS in the univariate analysis ( $p>0.05$ each). 
TABLE 1 | Patient and treatment characteristics.

\begin{tabular}{|c|c|c|}
\hline Characteristics & & $n(\%)$ \\
\hline \multirow[t]{2}{*}{ Gender } & Male & $35(77.8)$ \\
\hline & Female & $10(22.2)$ \\
\hline \multirow[t]{4}{*}{ Age, years } & Median (range) & $63(46-78)$ \\
\hline & $<60$ & $14(31.1)$ \\
\hline & 60-69.9 & $23(51.1)$ \\
\hline & $\geq 70$ & $8(17.8)$ \\
\hline ECOG PS & 0 & $45(100)$ \\
\hline \multirow[t]{4}{*}{ Etiology of LC } & HBV & $38(84.4)$ \\
\hline & $\mathrm{HCV}$ & $2(5.7)$ \\
\hline & Alcoholic & $2(5.7)$ \\
\hline & Unknown & $3(6.7)$ \\
\hline Child-Pugh classification & A & $45(100)$ \\
\hline \multirow[t]{3}{*}{ AFP, ng/mL } & Median (range) & $8.6(0.6-5543.3)$ \\
\hline & $<10$ & $24(53.3)$ \\
\hline & $\geq 10$ & $21(46.7)$ \\
\hline \multirow[t]{3}{*}{ Tumor size, cm } & Median (range) & $1.6(1.0-6.8)$ \\
\hline & $\leq 2$ & $28(62.2)$ \\
\hline & $>2$ & $17(37.8)$ \\
\hline \multirow[t]{2}{*}{ No. of treated lesions } & 1 & 42 (93.3) \\
\hline & 2 & $3(6.7)$ \\
\hline \multirow[t]{2}{*}{ TVT } & No & $44(97.8)$ \\
\hline & Branch & $1(2.2)$ \\
\hline \multirow[t]{3}{*}{ mUICC stage } & 1 & $16(35.6)$ \\
\hline & $\|$ & 24 (53.3) \\
\hline & III & $5(11.1)$ \\
\hline \multirow[t]{3}{*}{ BCLC stage } & A & 34 (75.6) \\
\hline & B & $10(22.2)$ \\
\hline & C & $1(2.2)$ \\
\hline \multirow[t]{2}{*}{ Diagnosis at PBT } & Primary & $8(17.8)$ \\
\hline & Recurrence & $37(82.2)$ \\
\hline \multirow[t]{5}{*}{ Pre-Tx to PBT site } & No & $14(31.1)$ \\
\hline & Yes & $31(68.9)$ \\
\hline & TACE & $25(80.7)$ \\
\hline & RFA & $5(16.1)$ \\
\hline & TACE + RFA & $1(3.2)$ \\
\hline \multirow[t]{7}{*}{ Pre-Tx to other sites } & No & $21(46.7)$ \\
\hline & Yes & 24 (53.3) \\
\hline & TACE & $10(41.7)$ \\
\hline & $\mathrm{SR}$ & $5(20.8)$ \\
\hline & $\begin{array}{l}\text { SR + TACE and/or } \\
\text { RFA }\end{array}$ & $4(16.7)$ \\
\hline & TACE + RFA & $3(12.5)$ \\
\hline & RFA & $2(8.3)$ \\
\hline Planning target volume, $\mathrm{cm}^{3}$ & Median (range) & $17.9(7.0-294.0)$ \\
\hline $\begin{array}{l}\text { Remaining normal liver } \\
\text { (RNL) volume, } \mathrm{cm}^{3}\end{array}$ & Median (range) & $\begin{array}{c}1,175.8 \\
(622.0-2,072.0)\end{array}$ \\
\hline RNL $\bigvee_{27 G y E}, \%$ & Median (range) & $6.6(3.6-17.6)$ \\
\hline Total liver (TL) volume, mL & Median (range) & $\begin{array}{c}1,215.5 \\
(646.0-2,121.0)\end{array}$ \\
\hline $\mathrm{TL} \mathrm{V}_{27 \mathrm{GyE}}, \%$ & Median (range) & $8.2(4.3-34.6)$ \\
\hline Stomach $D_{2 c c}, G y E$ & Median (range) & $0.0(0.0-34.3)$ \\
\hline
\end{tabular}

(Continued)
TABLE 1 | Continued

\begin{tabular}{llc}
\hline Characteristics & & $\boldsymbol{n}(\%)$ \\
\hline Esophagus $\mathrm{D}_{2 c c}$, GyE & Median (range) & $0.0(0.0-32.0)$ \\
Duodenum $\mathrm{D}_{2 c c}$, GyE & Median (range) & $0.0(0.0-22.6)$ \\
Bowel $\mathrm{D}_{2 c c}$, GyE & Median (range) & $0.0(0.0-17.5)$ \\
Cord $\mathrm{D}_{2 c c}$, GyE & Median (range) & $0.0(0.0-31.3)$ \\
\hline
\end{tabular}

LC, liver cirrhosis; HBV, hepatitis B virus; HCV, hepatitis C virus; AFP, a-fetoprotein; ECOG PS, Eastern Cooperative Oncology Group performance status; TVT, tumor vascular thrombosis; mUICC stage, modified International Union Against Cancer stage; BCLC stage, Barcelona Clinic Liver Cancer stage; TX, treatment; PBT, proton beam therapy; TACE, transarterial chemoembolization; RFA, radiofrequency ablation; $S R$, surgical resection; $R N L V_{27 G y E}$, relative volume of the remaining normal liver receiving $\geq 27$ GyE; ${ }_{T} L V_{27 G y E}$, relative volume of the total liver receiving $\geq 27$ GyE; $D_{2 c c}$, delivered radiation dose to the stomach, esophagus, duodenum, bowel, and spinal cord of $2 \mathrm{cc}\left(\mathrm{cm}^{3}\right)$; and GyE, gray equivalent.

All patients received the planned treatments without interruption of the treatment course. Within 3 months after PBT, of 45 patients, grades 1 and 2 elevated alanine aminotransferase without evidence of disease progression developed in $3(6.7 \%)$ and 0 patients $(0 \%)$, respectively, and the Child-Pugh score showed a 1-point decrease in two patients $(4.4 \%)$ and no change in 43 patients $(95.6 \%)$; 0 patients $(0 \%)$ had a $\geq 1$-point increase. Sixteen $(35.6 \%)$ and one $(2.2 \%)$ patients experienced grades 1 and 2 leukopenia, respectively, and 10 (22.2\%) and 0 (\%) experienced grades 1 and 2 thrombocytopenia, respectively. Thirteen patients (28.9\%) experienced grade 1 dermatitis, and no patient experienced grade $\geq 2$ or higher dermatitis. After 3 months from end date of PBT, late GI toxicity including ulcer and bleeding and late hepatic failure or death related to PBT had not occurred.

\section{DISCUSSION}

Curative treatments, such as surgical resection, liver transplantation, and local ablative treatments, including RFA, offering a 5-year OS rate of $50-70 \%(2-5,31)$, have been applied for selected BCLC 0/A HCC patients. For BCLC B HCC patients who have inoperable large or multifocal tumors not suitable for curative treatments, TACE is recommended as a first treatment with an expected median survival time of $>30$ months and a 3 -year OS rate of $40.4 \%(3-5,31,32)$. In our institutional cohort data (31), 3-year OS rates in mUICC I/II patients with Child-Pugh class A initially treated with surgical resection, liver transplantation, and RFA were $83,94.5$, and $100 \%$, respectively, and 3 -year OS rates in mUICC III patients with Child-Pugh class A treated with surgical resection, liver transplantation, and TACE were 56, 66.7, and 40.3\%, respectively. In the present study, PBT was applied to HCC patients who were failed after, were difficult to treat with, or refused to other local treatments, such as surgical resection, RFA, and TACE, and resulted in 3 -year OS rates of $86.4,85.9,100,100$, and $80.6 \%$ in all BCLC A, BCLC B, mUICC I, and mUICC II/III patients, respectively. Similarly, Fukuda et al. (20) reported that the 5-year OS rates in treatment-naive BCLC 0/A and B patients treated with PBT were 

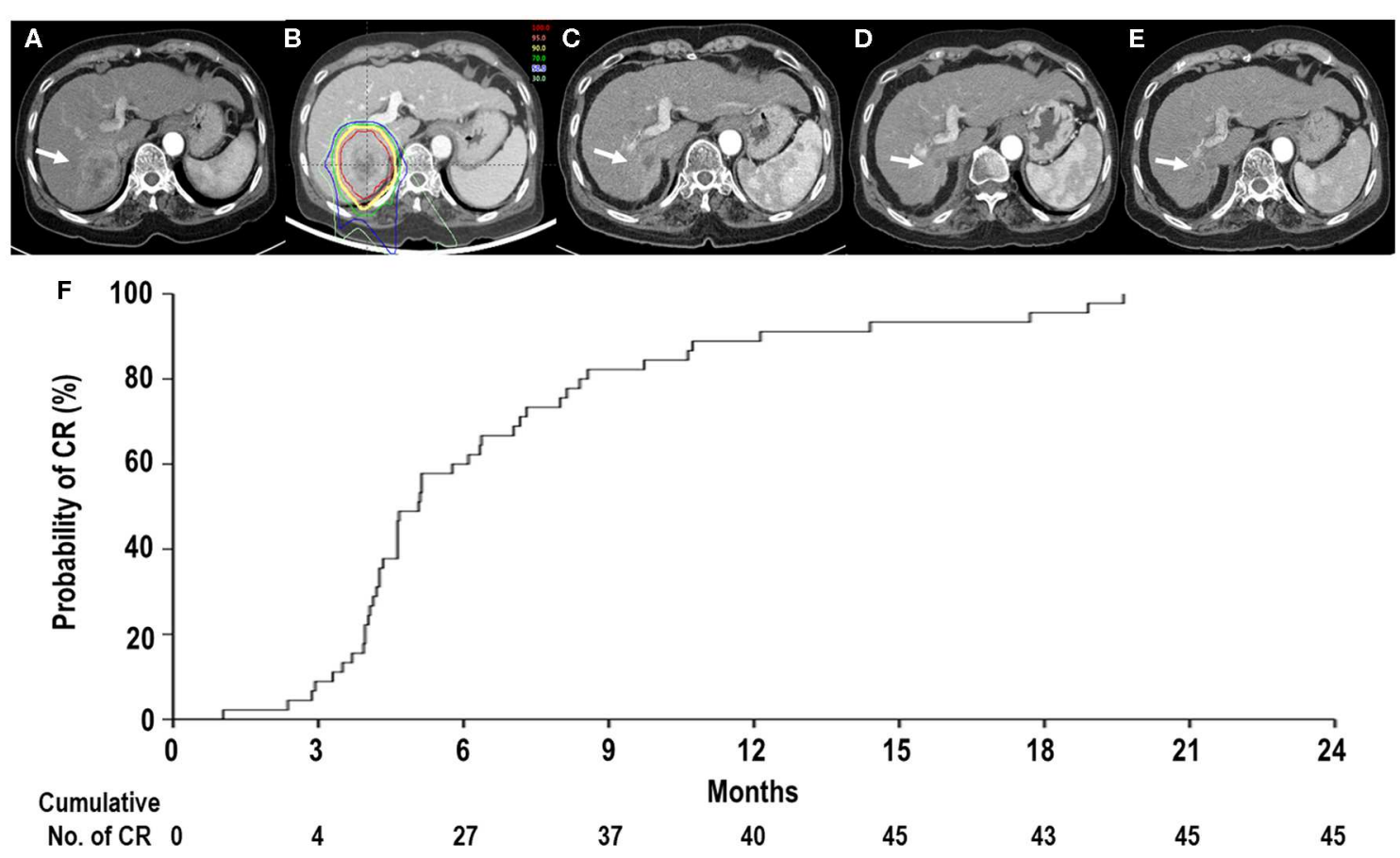

FIGURE 2 | Tumor response after proton beam therapy (PBT). (A) Computed tomography scans prior to PBT showing the tumor (arrow). (B) The patient received PBT. (C,D) Computed tomography scans at 4 and 11 months, respectively, after PBT showing shrinkage of the tumor (arrow). (E) Computed tomography scans at 14 months after PBT showing complete response (CR) of the tumor (arrow). (F) The actuarial CR probability curves of tumors after PBT.

\section{A Initial sites of disease progressions \\ $(n=23)$}

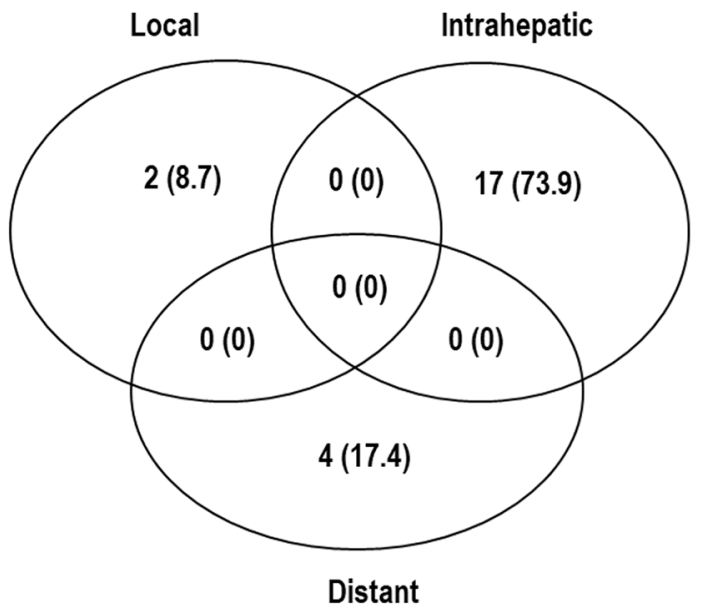

\section{B All sites of disease progressions}

$(n=23)$

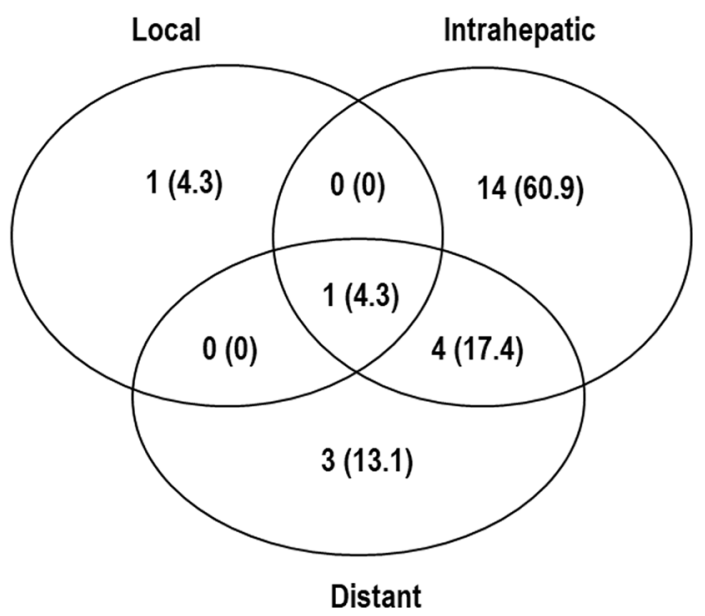

FIGURE 3 | Patterns of disease progressions. Initial sites (A) and all sites (B) of disease progression at the time of analysis.

69 and 66\%, respectively. Although direct comparisons among the studies are difficult because of different tumor burdens, patient characteristics, and selection bias, these results of PBT in BCLC $\mathrm{A} / \mathrm{B}$ patients were comparable to those of surgical resection, RFA, and TACE. Although there is no randomized study of PBT comparing with other local treatments, these findings suggested that PBT could be considered as one of the treatment modalities for these patients.

Treatments for HCC depend on various factors including tumor factors (i.e., stage, location, size, number, and echogenicity 


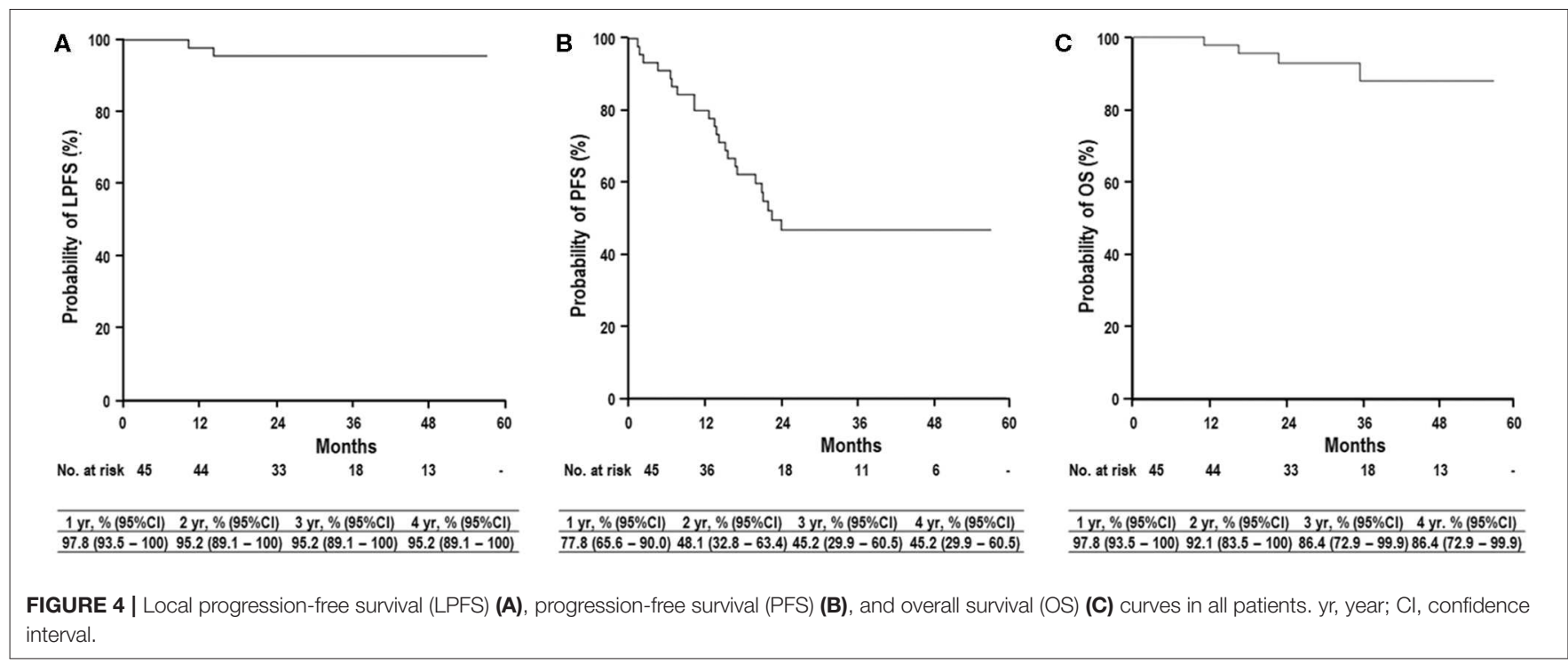

TABLE 2 | Univariate analysis of pretreatment characteristics for local progression-free survival (LPFS), progression-free survival (PFS), and overall survival (OS).

\begin{tabular}{|c|c|c|c|c|c|c|c|c|}
\hline \multirow[b]{2}{*}{ Characteristics } & & \multirow[b]{2}{*}{ No. of patients, $n$} & \multicolumn{2}{|l|}{ LPFS } & \multicolumn{2}{|l|}{ PFS } & \multicolumn{2}{|l|}{ os } \\
\hline & & & 3 years $(95 \% \mathrm{Cl}), \%$ & $p^{*}$ & 3 years $(95 \% \mathrm{Cl}), \%$ & $p^{*}$ & 3 years $(95 \% \mathrm{Cl}), \%$ & $p^{*}$ \\
\hline Gender & Female & 10 & $100(100)$ & & $27.4(0.0-59.2)$ & & $83.3(53.5-100)$ & \\
\hline \multirow[t]{2}{*}{ Age, years } & $<60$ & 14 & $92.9(79.4-100)$ & 0.600 & $50.0(32.0-66.4)$ & 0.590 & $91.7(76.0-100)$ & 0.663 \\
\hline & $\geq 60$ & 31 & $96.8(90.5-100)$ & & $42.8(23.7-76.3)$ & & $83.6(64.4-100)$ & \\
\hline Etiology of LC & Others & 7 & $100(100)$ & & $14.3(0-40.2)$ & & $68.6(32.1-100)$ & \\
\hline \multirow[t]{2}{*}{ AFP, ng/mL } & $<10$ & 24 & $95.8(87.8-100)$ & 0.949 & $49.3(27.7-70.9)$ & 0.288 & $91.0(79.0-100)$ & 0.940 \\
\hline & $\geq 10$ & 21 & $95.0(85.4-100)$ & & $40.6(18.8-62.4)$ & & $81.7(57.6-100)$ & \\
\hline \multirow[t]{2}{*}{ Tumor size, cm } & $<2$ & 27 & $96.4(89.5-100)$ & 0.764 & $52.2(32.0-72.4)$ & 0.192 & $95.5(86.9-100)$ & 0.183 \\
\hline & $\geq 2$ & 17 & $94.1(82.9-100)$ & & $35.3(12.6-58.0)$ & & $74.9(48.2-100)$ & \\
\hline No. of treated lesions & 1 & 42 & $95.1(88.4-100)$ & 0.698 & $43.4(27.3-59.5)$ & 0.566 & $85.5(71.0-100)$ & 0.588 \\
\hline mUICC stage & $\|/\| I I$ & 29 & $96.488 .8-100)$ & & $39.9(21.7-58.1)$ & & 80.6 (62.0-99.2) & \\
\hline \multirow[t]{2}{*}{ BCLC stage } & A & 34 & $93.9(85.7-100)$ & 0.422 & $43.7(26.3-61.1)$ & 0.885 & $85.9(70.4-100)$ & 0.835 \\
\hline & $\mathrm{B} / \mathrm{C}$ & 11 & $100(100)$ & & $50.9(19.0-82.8)$ & & $90.9(73.8-100)$ & \\
\hline \multirow[t]{2}{*}{ Diagnosis at PBT } & Primary & 8 & $100(100)$ & 0.498 & $72.9(40.6-100)$ & 0.115 & $100(100)$ & 0.304 \\
\hline & Recurrence & 37 & $94.3(86.7-100)$ & & 38.8 (22.1-55.5) & & 82.8 (65.7-99.9) & \\
\hline \multirow[t]{2}{*}{ Pre-Tx to PBT site } & No & 14 & $100(100)$ & 0.325 & $63.5(37.8-87.2)$ & 0.126 & $100(100)$ & 0.140 \\
\hline & Yes & 31 & $93.2(84.0-100)$ & & 36.1 (17.7-54.5) & & 79.3 (59.3-99.3) & \\
\hline \multirow[t]{2}{*}{ Pre-Tx to other sites } & No & 21 & $95.2(86.2-100)$ & 0.921 & $59.6(37.8-81.3)$ & 0.061 & $88.9(68.3-100)$ & 0.307 \\
\hline & Yes & 24 & $95.5(86.9-100)$ & & $31.4(10.8-52.0)$ & & $85.0(68.9-100)$ & \\
\hline
\end{tabular}

$\mathrm{Cl}$, confidence interval; CR, complete response; all others are the same as in Table 1.

* Log-rank test.

${ }^{\dagger}$ Two years.

of tumor), remaining liver function, availability of transplant donors, and patient comorbidities. Thus, as an alternative to conventional treatments including surgical resection, RFA, and TACE, RT including SBRT has been tried for HCC patients who have failed after, are difficult to treat with, or refuse to conventional treatment modalities $(3,6-8,21,33,34)$. A recent pooled analysis of SBRT using 24-60 Gy in three to six fractions (EQD2, 48-114.8 Gy $\mathrm{y}_{10}$; median, $83.3 \mathrm{~Gy}_{10}$ ) has shown a 3-year LPFS of $83.9 \%$ and a 3 -year OS of $48.3 \%$ (7). Wahl et al. (8) analyzed patients receiving SBRT $(n=63)$ and RFA $(n=161)$ and 
reported that the 2-year LPFS and OS rates were not significantly different ( 83.8 vs. $80.2 \%, p>0.05$; and 46.3 vs. $52.9 \%, p>$ 0.05 , respectively), but a recent analysis of the National Cancer Database data for treatment with SBRT $(n=296)$ and RFA $(n$ $=3,684$ ) showed that 5 -year OS was superior in RFA compared with SBRT (29.5 vs. $19.3 \%, p<0.01)$ (6). Proton beam therapy using 24-84 GyE in 4-34 fractions (EQD2, 28-103.5 GyE 10 ) has also been tried for patients with inoperable or recurrent HCC and has shown promising 2- or 3-year LPFS rates of 75-96\% and 2or 3-year OS rates of 45.1-66\% (13-24). Because results from a randomized study comparing $\mathrm{PBT}$ with SBRT are not available to date, whether PBT is truly equivalent or superior to SBRT or conventional treatment modalities for tumor control remains unanswered. However, our and others' dosimetric studies of PBT compared to RT with X-rays showed that PBT can reduce the irradiated liver volume at low to intermediate dose levels and subsequently may potentially decrease the risk of liver toxicity by allowing dose escalation for tumors (10-12). Meta-analysis showed a lower incidence of toxicity in PBT compared to RT with X-ray, with no significant difference in LPFS and OS (35), and Sanford et al. (36) showed PBT was superior to RT with Xray for OS by less liver toxicity. A recent systematic quantitative review of 13 SBRT studies for the HCC patients by Ohri et al. (34) did not show improvement of local tumor control by dose escalation. In a recent analysis of the National Cancer Database for T1-2N0 HCC patients treated with PBT $(n=71)$ or SBRT $(n=918)$, $\mathrm{PBT}$ and $\mathrm{EQD} 2$ of $>83 \mathrm{GyE}_{10}$ improved survival compared with SBRT and EQD2 of $<83 \mathrm{GyE}_{10}$, respectively (33). Our phase I dose-escalation study (17) showed that at least 78 $\mathrm{GyE}_{10}$ would be needed for local tumor control, and our previous studies of HCC patients with TVT $(n=41)$ and with/without TVT $(n=243)$ receiving risk-adapted PBT with 50-66 GyE in 10 fractions $(13,15)$ consistently showed that LPFS was superior at EQD2 of $\geq 80 \mathrm{GyE}_{10}$ compared with EQD2 of $<80 \mathrm{GyE}_{10}$. Although direct comparisons among the studies were difficult because of the heterogeneity of patient characteristics, different tumor loads, comorbidities, and selection bias, the EQD2 used in the present study (70 GyE in 10 fractions; EQD2, 99.2 $\mathrm{GyE}_{10}$ ) was at the high end of the range in the previous studies (EQD2, 28103.5 $\mathrm{GyE}_{10}$ ) and yielded the high end of LPFS and OS without grade $\geq 3$ toxicity $(17,19,22,23,30)$. These findings implied that dose escalation with PBT may improve local tumor control and survival by minimizing the risk of toxicity.

The present study included patients who had a tumor size and number of $\leq 7 \mathrm{~cm}$ and $\leq 2$, respectively, and/or $2 \mathrm{~cm}$ away from GI organs and Child-Pugh class A. Thus, further prospective and large-scale studies considering patients with large $(>7 \mathrm{~cm})$, multiple $(\geq 3)$ tumors and/or close to GI organs and Child-Pugh class $\mathrm{B} / \mathrm{C}$ are needed to define the role of PBT in HCC patients. Based on promising outcomes of PBT in present and previous studies (13-15), we conducted a prospective cohort study of HCC patients receiving PBT (NCC20180197) to comprehensively evaluate the role of PBT in HCC patients. Because of the lack of a randomized trial comparing PBT with current established treatments, surgical resection, RFA, TACE, and so on, it is still unclear to date whether PBT can truly achieve outcomes comparable to those treatments. However, Bush et al. (24), in preliminary results of a phase III trial comparing PBT with TACE, showed a trend toward superior local tumor control and lower toxicity for PBT compared with TACE. We conducted a phase III study comparing PBT with RFA for HCC patients with recurrent or residual disease (NCT01963429), and enrollment was completed and awaiting data maturation.

In conclusion, this study showed that PBT could achieve promising LPFS and OS similar to those of curative treatments in BCLC A/B HCC patients with Child-Pugh class A in our institutional cohort (31) and other studies (2-5, 31, 32), with minimal toxicity. Although further prospective large-scale studies of PBT for patients with unfavorable tumors (i.e., large and multiple tumors and close to GI organs) and poor liver function (i.e., Child-Pugh class B and C) are needed, our data suggest that PBT could be considered as one of the therapeutic options in HCC patients depending on the tumor burden and patient morbidities.

\section{DATA AVAILABILITY STATEMENT}

The datasets used and/or analyzed during the current study are available from the corresponding author upon reasonable request.

\section{ETHICS STATEMENT}

The studies involving human participants were reviewed and approved by Ethical Committee of National Cancer Center (NCC) (NCC20150042). The patients/participants provided their written informed consent to participate in this study.

\section{AUTHOR CONTRIBUTIONS}

TK, J-WP, and BK: conceptualization. EO, SY, SM, Y-HK, and DK: data collection. TK and SK: formal analysis. TK, J-WP, BK, SW, and WL: investigation. TK: writing original draft. J-WP, BK, and DK: supervision. All authors: reviewing and approval the final version of the manuscript.

\section{FUNDING}

This study was supported by a National Cancer Center Grant (NCC 1810271 and 1710030). The funding source had no role in the study design, data curation, or analysis and interpretation of data.

\section{ACKNOWLEDGMENTS}

The authors thank to Boram Park, Ph.D., biostatistics collaboration team, research core center, National Cancer Center, Goyang, Korea, for assisting the statistical analysis of this study. 


\section{REFERENCES}

1. Trevisani F, Cantarini MC, Wands JR, Bernardi M. Recent advances in the natural history of hepatocellular carcinoma. Carcinogenesis. (2008) 29:1299305. doi: 10.1093/carcin/bgn113

2. Galle PR, Forner A, Llovet JM, Mazzaferro V, Piscaglia F, Raoul JL, et al. EASL Clinical Practice Guidelines: Management of hepatocellular carcinoma. J Hepatol. (2018) 69:182-236. doi: 10.1016/j.jhep.2018. 03.019

3. Korean Liver Cancer Study Group and National Cancer Center, Korea. [Practice guidelines for management of hepatocellular carcinoma 2009]. Korean J Hepatol. (2009) 15:391-423. doi: 10.3350/kjhep.2009. 15.3.391

4. Korean Liver Cancer Study Group and National Cancer Center, Korea. 2014 KLCSG-NCC Korea Practice Guideline for the Management of Hepatocellular Carcinoma. Gut Liver. (2015) 9:267-317. doi: 10.5009/ gnl14460

5. Llovet JM, Bru C, Bruix J. Prognosis of hepatocellular carcinoma: the BCLC staging classification. Semin Liver Dis. (1999) 19:32938. doi: 10.1055/s-2007-1007122

6. Rajyaguru DJ, Borgert AJ, Smith AL, Thomes RM, Conway PD, Halfdanarson $\mathrm{TR}$, et al. Radiofrequency ablation versus stereotactic body radiotherapy for localized hepatocellular carcinoma in nonsurgically managed patients: analysis of the national cancer database. J Clin Oncol. (2018) 36:6008 doi: $10.1200 /$ JCO.2017.75.3228

7. Rim CH, Kim HJ, Seong J. Clinical feasibility and efficacy of stereotactic body radiotherapy for hepatocellular carcinoma: A systematic review and meta-analysis of observational studies. Radiother Oncol. (2019) 131:13544. doi: 10.1016/j.radonc.2018.12.005

8. Wahl DR, Stenmark MH, Tao Y, Pollom EL, Caoili EM, Lawrence TS, et al. Outcomes after stereotactic body radiotherapy or radiofrequency ablation for hepatocellular carcinoma. J Clin Oncol. (2016) 34:4529. doi: 10.1200/JCO.2015.61.4925

9. Lee KH, Yu JI, Park HC, Park SY, Shin JS, Shin EH, et al. Is higher dose always the right answer in stereotactic body radiation therapy for small hepatocellular carcinoma? Radiat Oncol J. (2018) 36:129-38. doi: 10.3857/roj.2017. 00598

10. Gandhi SJ, Liang X, Ding X, Zhu TC, Ben-Josef E, Plastaras JP, et al. Clinical decision tool for optimal delivery of liver stereotactic body radiation therapy: photons versus protons. Pract Radiat Oncol. (2015) 5:20918. doi: 10.1016/j.prro.2015.01.004

11. Kim JY, Lim YK, Kim TH, Cho KH, Choi SH, Jeong H, et al. Normal liver sparing by proton beam therapy for hepatocellular carcinoma: comparison with helical intensity modulated radiotherapy and volumetric modulated arc therapy. Acta Oncol. (2015) 54:1827-32. doi: 10.3109/0284186X.2015. 1009637

12. Wang X, Krishnan S, Zhang X, Dong L, Briere T, Crane $\mathrm{CH}$, et al. Proton radiotherapy for liver tumors: dosimetric advantages over photon plans. Med Dosim. (2008) 33:259-67. doi: 10.1016/j.meddos.2007. 04.008

13. Kim DY, Park JW, Kim TH, Kim BH, Moon SH, Kim SS, et al. Risk-adapted simultaneous integrated boost-proton beam therapy (SIBPBT) for advanced hepatocellular carcinoma with tumour vascular thrombosis. Radiother Oncol. (2017) 122:122-9. doi: 10.1016/j.radonc.2016. 12.014

14. Kim TH, Park JW, Kim BH, Kim DY, Moon SH, Kim SS, et al. Optimal time of tumour response evaluation and effectiveness of hypofractionated proton beam therapy for inoperable or recurrent hepatocellular carcinoma. Oncotarget. (2018) 9:4034-43. doi: 10.18632/oncotarget. 23428

15. Kim TH, Park JW, Kim BH, Kim H, Moon SH, Kim SS, et al. Does risk-adapted proton beam therapy have a role as a complementary or alternative therapeutic option for hepatocellular carcinoma? Cancers. (2019) 11:230. doi: 10.3390/cancers11020230

16. Kim TH, Park JW, Kim YJ, Kim BH, Woo SM, Moon SH, et al. Simultaneous integrated boost-intensity modulated radiation therapy for inoperable hepatocellular carcinoma. Strahlenther Onkol. (2014) 190:88290. doi: $10.1007 /$ s00066-014-0643-z
17. Kim TH, Park JW, Kim YJ, Kim BH, Woo SM, Moon SH, et al. Phase I dose-escalation study of proton beam therapy for inoperable hepatocellular carcinoma. Cancer Res Treat. (2015) 47:34-45. doi: 10.4143/crt.2013.218

18. Lee SU, Park JW, Kim TH, Kim YJ, Woo SM, Koh YH, et al. Effectiveness and safety of proton beam therapy for advanced hepatocellular carcinoma with portal vein tumor thrombosis. Strahlenther Onkol. (2014) 190:80614. doi: 10.1007/s00066-014-0604-6

19. Fukumitsu N, Sugahara S, Nakayama H, Fukuda K, Mizumoto M, Abei $\mathrm{M}$, et al. A prospective study of hypofractionated proton beam therapy for patients with hepatocellular carcinoma. Int J Radiat Oncol Biol Phys. (2009) 74:831-6. doi: 10.1016/j.ijrobp.2008.10.073

20. Fukuda K, Okumura T, Abei M, Fukumitsu N, Ishige K, Mizumoto $\mathrm{M}$, et al. Long-term outcomes of proton beam therapy in patients with previously untreated hepatocellular carcinoma. Cancer Sci. (2017) 108:497503. doi: 10.1111/cas.13145

21. Bujold A, Massey CA, Kim JJ, Brierley J, Cho C, Wong RK, et al. Sequential phase I and II trials of stereotactic body radiotherapy for locally advanced hepatocellular carcinoma. J Clin Oncol. (2013) 31:16319. doi: 10.1200/JCO.2012.44.1659

22. Chiba T, Tokuuye K, Matsuzaki Y, Sugahara S, Chuganji Y, Kagei $\mathrm{K}$, et al. Proton beam therapy for hepatocellular carcinoma: a retrospective review of 162 patients. Clin Cancer Res. (2005) 11:3799-805. doi: 10.1158/1078-0432.CCR-04-1350

23. Kawashima M, Furuse J, Nishio T, Konishi M, Ishii H, Kinoshita T, et al. Phase II study of radiotherapy employing proton beam for hepatocellular carcinoma. J Clin Oncol. (2005) 23:1839-46. doi: 10.1200/JCO.2005.00.620

24. Bush DA, Smith JC, Slater JD, Volk ML, Reeves ME, Cheng J, et al. Randomized clinical trial comparing proton beam radiation therapy with transarterial chemoembolization for hepatocellular carcinoma: results of an interim analysis. Int J Radiat Oncol Biol Phys. (2016) 95:47782. doi: 10.1016/j.ijrobp.2016.02.027

25. Ueno S, Tanabe G, Nuruki K, Hamanoue M, Komorizono Y, Oketani $M$, et al. Prognostic performance of the new classification of primary liver cancer of Japan (4th edition) for patients with hepatocellular carcinoma: a validation analysis. Hepatol Res. (2002) 24:395-403. doi: 10.1016/S1386-6346(02)00144-4

26. Takeda A, Oku Y, Sanuki N, Kunieda E, Koike N, Aoki Y, et al. Dose volume histogram analysis of focal liver reaction in follow-up multiphasic CT following stereotactic body radiotherapy for small hepatocellular carcinoma. Radiother Oncol. (2012) 104:374-8. doi: 10.1016/j.radonc.2011. 12.008

27. Joiner MC Bentzen SM. Time-dose relationships: the linear-quadrantic approach. In: Steel GG, editor. Basic Clinical Radiobiology. New York, NY: Oxford University Press (2003).

28. Kim TH, Kim DY, Park JW, Kim SH, Choi JI, Kim HB, et al. Dose-volumetric parameters predicting radiation-induced hepatic toxicity in unresectable hepatocellular carcinoma patients treated with threedimensional conformal radiotherapy. Int J Radiat Oncol Biol Phys. (2007) 67:225-31. doi: 10.1016/j.ijrobp.2006.08.015

29. Lencioni R, Llovet JM. Modified RECIST (mRECIST) assessment for hepatocellular carcinoma. Semin Liver Dis. (2010) 30:5260. doi: 10.1055/s-0030-1247132

30. Bush DA, Kayali Z, Grove R, Slater JD. The safety and efficacy of high-dose proton beam radiotherapy for hepatocellular carcinoma: a phase 2 prospective trial. Cancer. (2011) 117:3053-9. doi: 10.1002/cncr.25809

31. Kwak HW, Park JW, Nam BH, Yu A, Woo SM, Kim TH, et al. Clinical outcomes of a cohort series of patients with hepatocellular carcinoma in a hepatitis B virus-endemic area. J Gastroenterol Hepatol. (2014) 29:8209. doi: 10.1111/jgh. 12470

32. Lencioni R, de Baere T, Soulen MC, Rilling WS, Geschwind JF. Lipiodol transarterial chemoembolization for hepatocellular carcinoma: a systematic review of efficacy and safety data. Hepatology. (2016) 64:106-16. doi: 10.1002/hep.28453

33. Hasan S, Abel S, Verma V, Webster P, Arscott WT, Wegner RE, et al. Proton beam therapy versus stereotactic body radiotherapy for hepatocellular carcinoma: practice patterns, outcomes, and the effect of biologically effective dose escalation. J Gastrointest Oncol. (2019) 10:9991009. doi: 10.21037/jgo.2019.08.03 
34. Ohri N, Tome WA, Mendez Romero A, Miften M, Ten Haken RK, Dawson LA, et al. Local control after stereotactic body radiation therapy for liver tumors. Int J Radiat Oncol Biol Phys. (2018). doi: 10.1016/j.ijrobp.2017.12.288. [Epub ahead of print].

35. Qi WX, Fu S, Zhang Q, Guo XM. Charged particle therapy versus photon therapy for patients with hepatocellular carcinoma: a systematic review and meta-analysis. Radiother Oncol. (2015) 114:289-95. doi: 10.1016/j.radonc.2014.11.033

36. Sanford NN, Pursley J, Noe B, Yeap BY, Goyal L, Clark JW, et al. Protons versus photons for unresectable hepatocellular carcinoma: liver decompensation and overall survival. Int J Radiat Oncol Biol Phys. (2019) 105:64-72. doi: 10.1016/j.ijrobp.2019.01.076
Conflict of Interest: The authors declare that the research was conducted in the absence of any commercial or financial relationships that could be construed as a potential conflict of interest.

Copyright (c) 2020 Kim, Park, Kim, Oh, Youn, Moon, Kim, Woo, Koh, Lee and Kim. This is an open-access article distributed under the terms of the Creative Commons Attribution License (CC BY). The use, distribution or reproduction in other forums is permitted, provided the original author(s) and the copyright owner(s) are credited and that the original publication in this journal is cited, in accordance with accepted academic practice. No use, distribution or reproduction is permitted which does not comply with these terms. 